\title{
ERRATA
}

(July, Journal of Metals, pp. 24-29)

\section{Recuperator Alloys for High-Temperature Waste Heat Recovery}

G.Y. Lai, M.F. Rothman, S. Baranow, and R.B. Herchenroeder

The following figures are the correct Figures 1, 5, and 6 for this article published in the July issue.

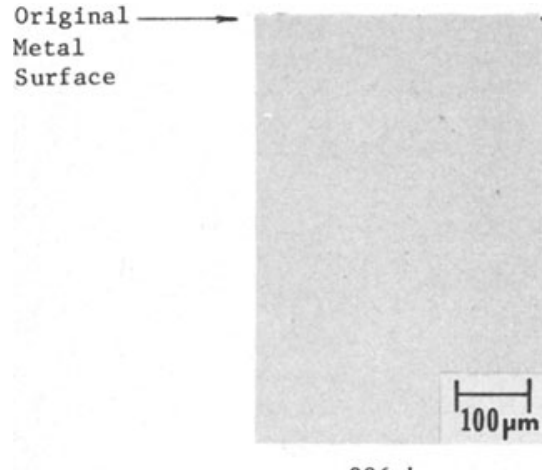

CABOT alloy No. 214

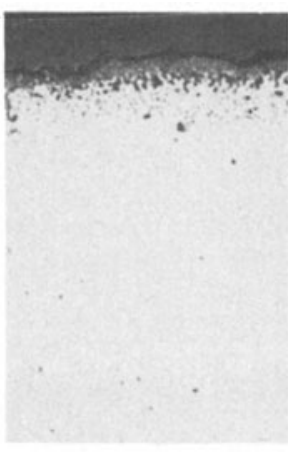

$432 \mathrm{~h}$

HASTELLOY alloy $\mathrm{X}$

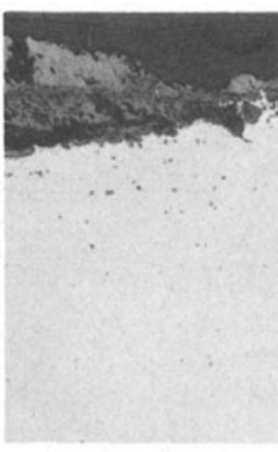

$373 \mathrm{~h}$

Type $310 \mathrm{SS}$

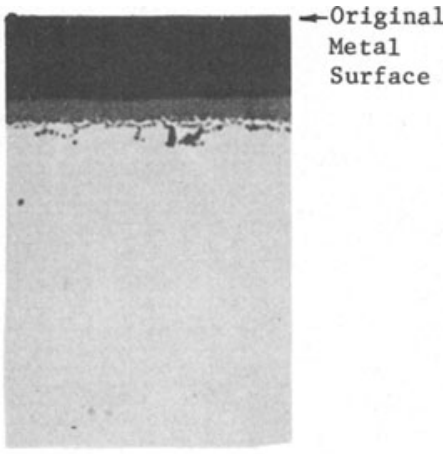

$180 \mathrm{~h}$

Alloy 600

Figure. 1. Oxidation resistance of several high-temperature alloys. Samples were exposed in still air at $2100^{\circ} \mathrm{F}\left(1150^{\circ} \mathrm{C}\right)$ for times indicated. See Table I for compositions.

Figure 5. Optical photomicrographs showing corrosion attack upon various alloys in $\mathrm{Ar}-20 \% \mathrm{O}_{2}-2 \% \mathrm{Cl}_{2}$ at $1650^{\circ} \mathrm{F}$ $\left(900^{\circ} \mathrm{C}\right) / 8 \mathrm{~h}$.

Figure 6. Optical photomicrographs showing corrosion attack upon various alloys in $\mathrm{Ar}-4 \% \mathrm{H}_{2}-4 \% \mathrm{HCl}$ at $1650^{\circ} \mathrm{F}$ $\left(900^{\circ} \mathrm{C}\right) / 8 \mathrm{~h}$.
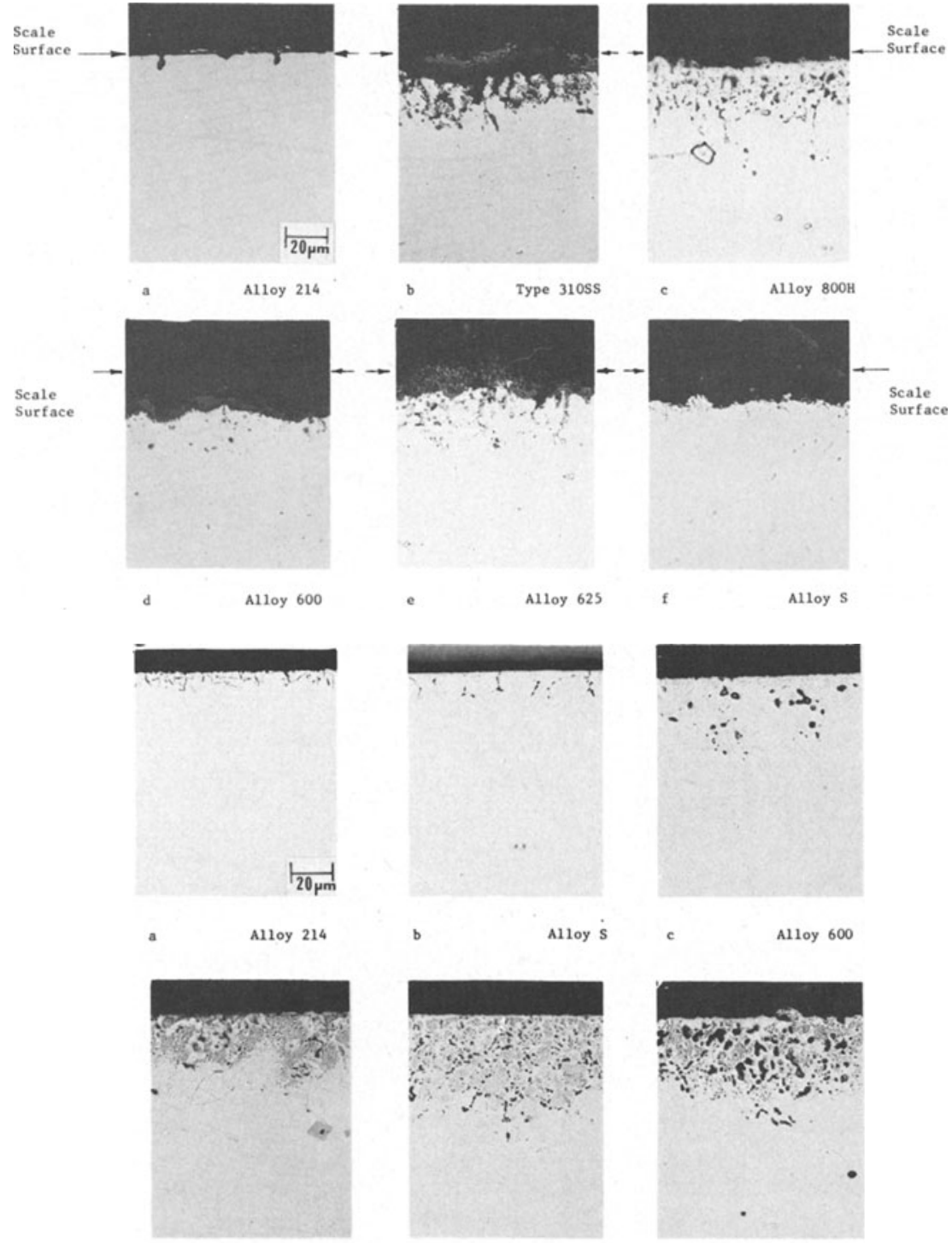

Alloy $800 \mathrm{H}$
A11oy 625

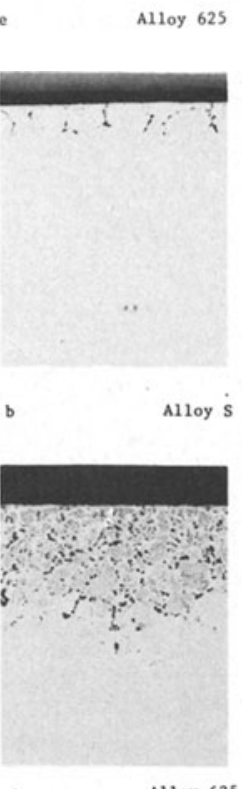

A11oy 625
Alloy $\mathrm{S}$

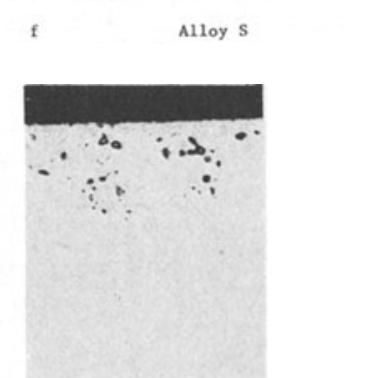

Alloy 600

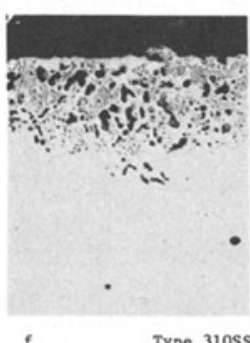

Type $310 \mathrm{~s}$ 